
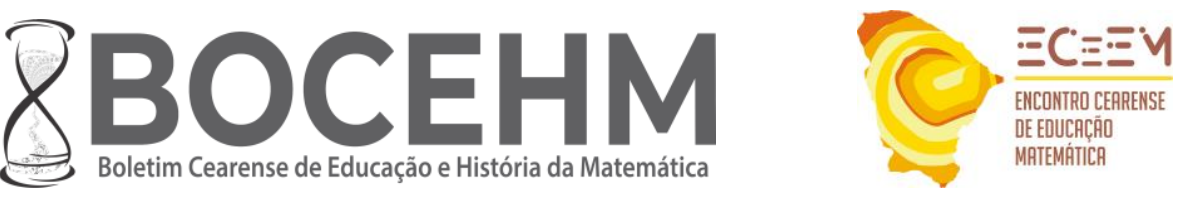

ISSN: $2447-8504$

DOI: $10.30938 /$ bocehm.v8i23.4998

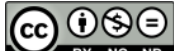

\title{
POSSIBILIDADES DE DESENVOLVIMENTO DO PENSAMENTO ALGÉBRICO A PARTIR DE TAREFAS NOS ANOS INICIAIS
}

\section{POSSIBILITIES FOR DEVELOPING ALGERIC THINKING FROM TASKS IN THE INITIAL YEARS}

\author{
Jocelei Miranda da Silva ${ }^{1}$; Klinger Teodoro Ciríaco ${ }^{2}$
}

\begin{abstract}
RESUMO
Descrevemos parte integrante de uma investigação de mestrado, vinculada ao Programa de PósGraduação em Educação Matemática da Universidade Federal de Mato Grosso do Sul PPGEdumat/UFMS, cujo o objetivo do presente texto reside em caracterizar o termo "pensamento algébrico" a partir dos autores/estudiosos da área, bem como levantar indicadores de problematização de tarefas matemáticas, a partir de uma apreciação crítica de materiais produzidos por grupos de pesquisas brasileiros e internacionais, das possibilidades com crianças do Ensino Fundamental I. Diante da propositura do artigo, acreditamos que tal análise contribuirá para a atuação de professores dos anos iniciais, uma vez que a unidade temática "Álgebra" constitui-se desafio à formação inicial e contínua, particularmente no solo brasileiro. A abordagem metodológica localiza-se na descrição e análise da natureza das tarefas, as quais sinalizam para a abordagem de regularidades, padrões e generalização. No contexto do que aqui apresentamos, buscamos nos aproximar destes estudos com intuito de aprimorar a compreensão dos caminhos existentes, bem como a sinalização que as mesmas comunicam para a necessidade de constituição de espaços formativos centrados na escola, que possibilitem o desenvolvimento da prática docente, especialmente em relação às propriedades relativas ao desenvolvimento do pensamento algébrico com as crianças no início da escolarização. A partir da análise dos materiais referenciados, a expectativa é que os resultados das propostas possam contribuir para uma melhor compreensão dos atributos e aspectos definidores de objetos de ensino do campo algébrico e também que a prática colaborativa recorrida nos ambientes articuladores destas, possam demarcar
\end{abstract}

\footnotetext{
${ }^{1}$ Graduação em Ciências - Habilitação em Matemática - pela Universidade Estadual de Mato Grosso do Sul (UEMS). Mestrando em Educação Matemática pelo Programa de Pós-Graduação em Educação Matemática (PPGEduMat) do Instituto de Matemática (INMA) da Universidade Federal de Mato Grosso do Sul (UFMS) na linha de pesquisa "Formação de Professores e Currículo", Campo Grande, MS, Brasil. Integrante do "MANCALA - Grupo de Estudos e Pesquisas em Educação Matemática, Cultura e Formação Docente" (CNPq). Cidade Universitária, s/n- Caixa Postal 549. Avenida Senador Filinto Müller ${ }^{\circ} 1555$, Campo Grande, MS, Brasil. CEP: 79074-460. E-mail: joceleims@ gmail.com.

(iD) ORCID iD: https://orcid.org/0000-0003-4571-4325.

${ }^{2}$ Doutor em Educação pela Faculdade de Ciências e Tecnologia da Universidade Estadual Paulista "Júlio de Mesquita Filho" (FCT/UNESP, Presidente Prudente-SP). Professor Adjunto do Departamento de Teorias e Práticas Pedagógicas (DTPP) do Centro de Educação e Ciências Humanas (CECH) da Universidade Federal de São Carlos (UFSCar), São Carlos, SP, Brasil. Líder do "MANCALA - Grupo de Estudos e Pesquisas em Educação Matemática, Cultura e Formação Docente" (CNPq/UFSCar). Rodovia Washington Luís S/N KM 235 - Jardim Guanabara, São Carlos, SP, Brasil, CEP: 13565-905. E-mail: klinger.ciraco@ufscar.br

(iD) ORCID iD: https://orcid.org/0000-0003-1694-851X.
} 
espaços de aprendizagens docentes em relação à ampliação do repertório didático-pedagógico e conceitual

Palavras-chave: Pensamento algébrico; Anos Iniciais; Tarefas matemáticas.

\begin{abstract}
We describe an integral part of a master's research, linked to the Graduate Program in Mathematics Education at the Federal University of Mato Grosso do Sul - PPGEdumat / UFMS, whose objective is to characterize the term "algebraic thinking" from the authors / scholars in the field, as well as raising indicators of problematization of mathematical tasks, based on a critical appreciation of materials produced by Brazilian and international research groups, of the possibilities with elementary school children I. Given the proposal of the article, we believe that such analysis will contribute to the performance of teachers in the early years, since the thematic unit "Algebra" is a challenge to initial and continuing education, particularly on Brazilian soil. The methodological approach is based on the description and analysis of the nature of the tasks, which signal the approach to regularities, patterns and generalization. In the context of what we present here, we seek to approach these studies in order to improve the understanding of the existing paths, as well as the signaling that they communicate to the need for constitution of training spaces centered on the school, which enable the development of teaching practice, especially in relation to the properties related to the development of algebraic thinking with children at the beginning of schooling. From the analysis of the referenced materials, the expectation is that the results of the proposals can contribute to a better understanding of the attributes and defining aspects of teaching objects in the algebraic field and also that the collaborative practice used in the articulating environments of these, can demarcate spaces of teaching learning in relation to the expansion of the didactic-pedagogical and conceptual repertoire
\end{abstract}

Keywords: Algebraic thinking; Early Years; Mathematical tasks. 


\section{Introdução}

Este texto dialoga com parte da produção da dissertação de mestrado, vinculada ao Programa de Pós-Graduação em Educação Matemática da Universidade Federal de Mato Grosso do Sul (UFMS), que estamos a desenvolver desde março de 2020, na qual objetivamos compreender em que medida a experiência de trabalho colaborativo contribui para análise, elaboração e desenvolvimento de tarefas que promovam o pensamento algébrico no ciclo da alfabetização $\left(1^{\circ}\right.$ ao $3^{\circ}$ ano). Dado o recorte temático, intenciona-se com o desenvolvimento deste artigo, compartilhar encaminhamentos da apreciação crítica de materiais produzidos por grupos de pesquisas brasileiros e internacionais que trazem propostas de tarefas matemáticas que envolvem raciocínio algébrico.

Para este fim, o trabalho encontra-se estruturado em quatro seções. Na primeira seção está o referencial teórico, em que buscamos caracterizar o que é pensamento algébrico com base na literatura estudada. O delimineamento metodológico é destacado na segunda parte, em que apresentamos a natureza da abordagem e o tipo de análise empreendida (análise documental) de alguns cadernos com tarefas para sala de aula, buscando extrair algumas propostas de trabalhos matemáticos que correlacionam com as propriedades matemáticas ligadas ao pensamento algébrico que a Base Nacional Comum Curricular (BNCC) descreve. Já na terceira, traremos algumas proposições de tarefas matemáticas, bem como analises de como as mesmas podem contribuir na articulação de propriedades matemáticas propostas pela BNCC e o seu desenvolvimento no contexto da sala de aula. E por fim, refletiremos sobre como essa caracterização do pensamento algébrico pode ser explorada mediante as tarefas matemáticas e os contributos que essas atividades trarão para os professores, que tem esse desafio em trabalhar esse eixo temático nesta etapa da escolarização.

\section{Pensamento algébrico: o que é?}

Tendo em vista algumas reformas na trajetória do currículo de Matemática no Brasil observa-se, em alguns momentos, proposituras no sentido de avançar na aprendizagem das crianças na busca da produção de sentidos para suas representações. Visando fundamentar em parte esta reflexão, nesta seção discutiremos aspectos da inserção do pensamento algébrico no âmbito da revisão curricular que vem ocorrendo em 
nosso país com a implementação da Base Nacional Comum Curricular - BNCC (BRASIL, 2018). Em uma apreciação do presente documento, localizamos a presença de um campo novo de atuação para os professores licenciados em Pedagogia: o eixo temático "Álgebra".

[...] o trabalho com a álgebra, no início da escolaridade, contribui para que os/as estudantes desenvolvam um tipo de raciocínio específico, denominado pensamento algébrico. Essa ideia, atualmente considerada, diferencia-se de uma ideia de álgebra escolar como um processo de manipulação de símbolos. Nessa perspectiva, algumas dimensões do trabalho com a álgebra estão presentes nos processos de ensino e de aprendizagem, desde os anos iniciais, como as ideias de regularidade, de generalização e de equivalência (BRASIL 2018, p. 278).

No entanto, a título de contextualização do problema ora destacado, percebemos que a BNCC, muito embora destaque a linguagem algébrica em suas orientações, deixa à desejar pela ausência considerável de elementos que poderiam trazer orientações e indicadores de atuação para a organização do trabalho pedagógico e conhecimento do professor para a consequente promoção da aprendizagem dos alunos ocorra de modo mais significativo.

Em defesa da inclusão do pensamento algébrico, desde a mais tenra idade, Canavarro (2007, p. 88) explica que a ausência da construção de processos ligados à Álgebra, no ciclo da alfabetização, se deve ao fato de que existe uma visão errônea em relação à ela, visto que a "[...] álgebra escolar tem estado associada à manipulação dos símbolos e à reprodução de regras operatórias, tantas vezes aplicadas mecanicamente e sem compreensão [...]". Contudo, o que se quer com o estudo da "Álgebra" no início da escolarização é pensar que no:

[...] cerne do pensamento algébrico estão os significados, está o uso dos símbolos como recurso para representar ideias gerais resultantes do raciocínio com compreensão. Trata-se de olhar através dos símbolos e não de olhar os símbolos (KAPUT; BLANTON; MORENO, 2008, p. 88).

A integração da Álgebra nos anos iniciais seria adequada não somente para o desenvolvimento da capacidade cognitiva das crianças, mas também, para que estas sejam encorajadas a construírem significados e, dessa forma, possam ter a minimização de possíveis dificuldades no ciclo de ensino subsequente da Educação Básica (anos finais do Ensino Fundamental). A defesa da presença de uma perspectiva de trabalho docente que 
envolvem o pensar algebricamente centra-se no fato de que é preciso que se compreenda melhor essa área do saber matemático e enaltecer de habilidades algébricas recorrentes no cotidiano como, por exemplo, situações em que a criança irá identificar determinadas regularidades na solução de tarefas e estabelecer padrões de resoluções, isso poderia ser desenvolvido em algum jogo, pequenas transações financeiras ou, até mesmo, resolução de problemas.

Para além de exemplos práticos, em uma tentativa de definir pensamento algébrico, do ponto de vista conceitual, Canavarro (2007, p. 87) cita ainda que o "[...] reconhecimento daquilo que é geral numa dada situação matemática e à expressão dessa generalização". Blanton e Kaput (2005, p. 413) reforçam esse conceito afirmando que o mesmo é um processo por meio do qual os estudantes:

[...] generalizam ideias matemáticas a partir de um conjunto de casos particulares, estabelecem essas generalizações através de discurso argumentativo, e expressam-nas de formas progressivamente mais formais e adequadas à sua idade.

Seguindo a mesma perspectiva, Meira (2003 p. 19) afirma a importância em priorizar a construção do pensamento algébrico nos anos iniciais do Ensino Fundamental, pois é o momento da fase escolar em que a criança inicia a produção de significados em relação aos conhecimentos compartilhados e, a partir daí, poderá "[...] estabelecer relações entre os conceitos, as ferramentas que utilizamos para construí-los (computadores ou registros escritos, por exemplo) e as atividades nas quais os conceitos emergem (por exemplo, durante a resolução de problemas)".

No entanto, se esse estabelecimento conceitual é protelado para a segunda fase do Ensino Fundamental percebe-se a formação de alunos "meros repetidores" de fórmulas e regras, que resolvem de forma mecânica as situações-problemas que lhes são propostas, gerando uma enorme lacuna em seu aprendizado ao apresentarem dificuldades na falta de conexão entre as tarefas que resolvem (CASTRO, 2003). Sobre essa questão, Castro (2003, p. 6) argumenta que "[...] melhores resultados têm sido alcançados quando alunos iniciam a educação algébrica desde as séries iniciais da escola básica [...]", pois o professor poderá introduzir o "fazer algébrico", desconsiderando nesse momento a mera utilização de letras e trabalhando os significados da atividade algébrica de forma concreta 
na busca da produção de significados adequados para as descobertas simbólicas da criança.

Em síntese, diante do exposto, acreditamos que implementar na sala de aula dos anos iniciais tarefas que impliquem no desenvolvimento do pensamento algébrico é um desafio aos professores, isso porque a unidade temática nova, campo de atuação anteriormente mais explícito a partir dos anos finais do Ensino Fundamental, coloca em xeque outros elementos centrais para sua efetivação: a formação docente e o conhecimento "de" e "sobre" Álgebra do pedagogo. Neste sentido, analisar a natureza de algumas propostas indicadas para o trabalho com a presente área nos primeiros anos julgamos ser pertinente no sentido de colocar em destaque o que se intenciona com a exploração de determinadas habilidades a partir da linguagem algébrica, o que ocorrerá nas próximas seções do artigo.

\section{Delineamento metodológico}

Com uma abordagem de natureza qualitativa (BOGDAN; BIKLEN, 1994), buscamos descrever como ocorreu o processo de análise e apreciação de algumas tarefas matemáticas, que envolvem processos algébricos indicadas ao trabalho nos anos iniciais em materiais de orientação à formação e atuação do professor que ensina Matemática. Nosso interesse é apresentar e discutir ideias de tarefas que envolvam o pensamento algébrico e sua exploração como contextualização do que estamos a falar quando afirmase, na literatura da área, a inserção da Álgebra nos primeiros anos. Para este fim, a intenção é destacar alguns projetos que já trabalham de forma colaborativa e os resultados produzidos mediante a investigação de pesquisadores nacionais (NACARATO; CUSTÓDIO, 2018) e internacionais (PONTE; BRANCO; MATOS, 2009). Certos de que o estudo destes materiais irão produzir reflexões no planejamento docente em futuras intervenções, elegemos 4 tarefas apresentadas pelos autores em suas obras, das quais realizamos uma interpretação das possibilidades de atuação frente aos objetivos de cada uma delas no trabalho em sala de aula.

A obra brasileira apreciada trata-se do e-book organizado por Nacarato e Custódio (2018), disponibilizada pela Sociedade Brasileira de Educação Matemática (SBEM), "O desenvolvimento do pensamento algébrico na educação básica: compartilhando propostas de sala de aula com o professor que ensina (ensinará) Matemática". 
O trabalho descrito no $e$-book envolve dados de um projeto de investigação desenvolvido pelo Grupo Colaborativo em Matemática - GRUCOMAT - da Universidade São Francisco (UFS) de Itatiba (SP), cujos os resultados têm contribuído, sobremaneira, para pensarmos ações com professoras dos anos iniciais em nossa investigação de mestrado.

O outro material apreciado, a obra internacional, é uma publicação do Ministério da Educação de Portugal assinada por Ponte, Branco e Matos (2009) intitulada "Álgebra no Ensino Básico" que, segundo os pesquisadores, "[...] constitui um material de apoio ao trabalho dos professores no âmbito do Programa de Matemática do Ensino Básico" (p. 3 destaques dos autores).

Com base nas orientações da BNCC, quando o documento define "objetos e conhecimento" e "habilidades", particularmente no que respeito à Álgebra, buscamos tentar localizar nos encartes formativos das duas obras tarefas que possibilitassem perceber, de modo mais explícito, elementos expostos na base, isso para que o professor em exercício tenha possibilidades mais exitosas de compreender como as propriedades algébricas nos anos iniciais se materializam em uma situação didática.

Assim, realizamos a leitura crítica dos materiais de Nacarato e Custódio (2018), bem como de Ponte, Branco e Matos (2009), os quais deram-nos fundamento para a descrição e análise que seguirá na próxima seção. Acreditamos que a exploração/apresentação da natureza das tarefas que envolvem pensamento algébrico poderão fornecer subsídios teórico-metodológicos para trabalhos futuros, assim como para a própria pesquisa-ação que pretendemos implementar, a partir de março de 2021, no estudo mais alargado que integra as reflexões expressas neste artigo.

\section{Possibilidades de abordagem das propriedades do pensamento algébrico nos anos iniciais presentes nas tarefas analisadas}

Partindo do referenciado adotado neste trabalho, é importante distinguir os conceitos de "tarefa" e "atividade". Ponte (2014, p. 16) destaca que as tarefas "[...] são ferramentas de mediação fundamentais no ensino e na aprendizagem da Matemática". Neste sentido, uma tarefa pode ter ou não "[...] potencialidades em termos de conceitos e processos matemáticos que pode ajudar a mobilizar". A tarefa pode ainda dar espaço para diversas atividades, de acordo com "[...] o modo como for proposta, a forma de 
organização do trabalho dos alunos, o ambiente de aprendizagem, e a sua própria capacidade e experiência anterior" (PONTE, 2014, p. 16). Logo, podemos inferir, na leitura interpretativa do termo "tarefa", que esta é uma ação do docente quando propõe algo a ser problematizado em sala de aula e, portanto, trata-se de algo ligado à figura do professor.

Por outro lado, a atividade:

[...] corresponde a uma ou mais tarefas realizadas no quadro de uma certa situação. É pela sua atividade e pela sua reflexão sobre essa atividade que o aluno aprende mas é importante ter presente que esta depende de dois elementos igualmente importantes: (i) a tarefa proposta; e (ii) a situação didática criada pelo professor (PONTE, 2014, p. 16)

Desse modo, podemos afirmar que as atividades desenvolvidas em sala de aula contribuirão muito na construção da aprendizagem, visto que as atividades integram o movimento da realização de diversas tarefas importantes neste processo. Quando nos referimos às atividades, incluímos os âmbitos físico e mental pertinentes ao aluno e ao contexto que está inserido (PONTE, 2014). Sendo assim, ao atentarmos para as características do trabalho que iremos desenvolver no ambiente da escola, intencionamos viabilizar tarefas aos alunos que os encorajem à aprender e a relacionarem os conhecimentos aprendidos com os saberes adquiridos anteriormente.

Sendo assim, na perspectiva de contribuir com as discussões da área e especialmente ao trabalho docente, destacaremos algumas tarefas e seus referidos objetivos quando o foco torna-se promover o pensamento algébrico no ciclo da alfabetização ( $1^{\circ}$ ao $3^{\circ}$ ano).

A tarefa 1 destina-se ao $1^{\circ}$ ano e perspectiva trabalhar sequência de repetição. Camargo, Bagne, Bologani e Coletti (2018) sugerem esta tarefa cujo objetivo centra-se na forma com que os triângulos se repetem, exemplificamos a primeira sequência sendo a repetição dada: triângulo azul e triângulo vermelho (Figura 1).

Figura 1 - Sequência de triângulos
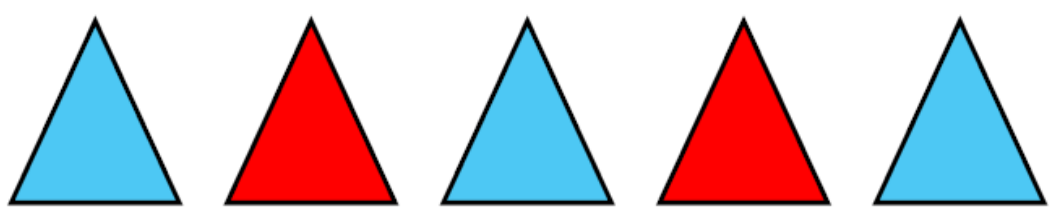
Fonte: Camargo, Bagne, Bologani e Coletti (2018, p. 35)

Seguindo intencionalidade semelhante, as autoras ainda recomendam que sejam exploradas com as crianças outras opções de desenvolvimento sequenciais por meio de materiais manipulativos (estruturados ou não) como, por exemplo, na formação de uma pulseira e/ou colar de contas. Nesta proposta, é orientado que as crianças possam utilizar um fio de contas de uma a três cores em que, juntamente com os colegas, irão formular questões para o outro grupo responder na tentativa de analisar o colar e justificar a sequência de cores por algum padrão existente, que possibilite reunir argumentos com inserção de vocabulário matemático em justificação ao motivo da sequência.

Figura 2 - Pulseira de contas

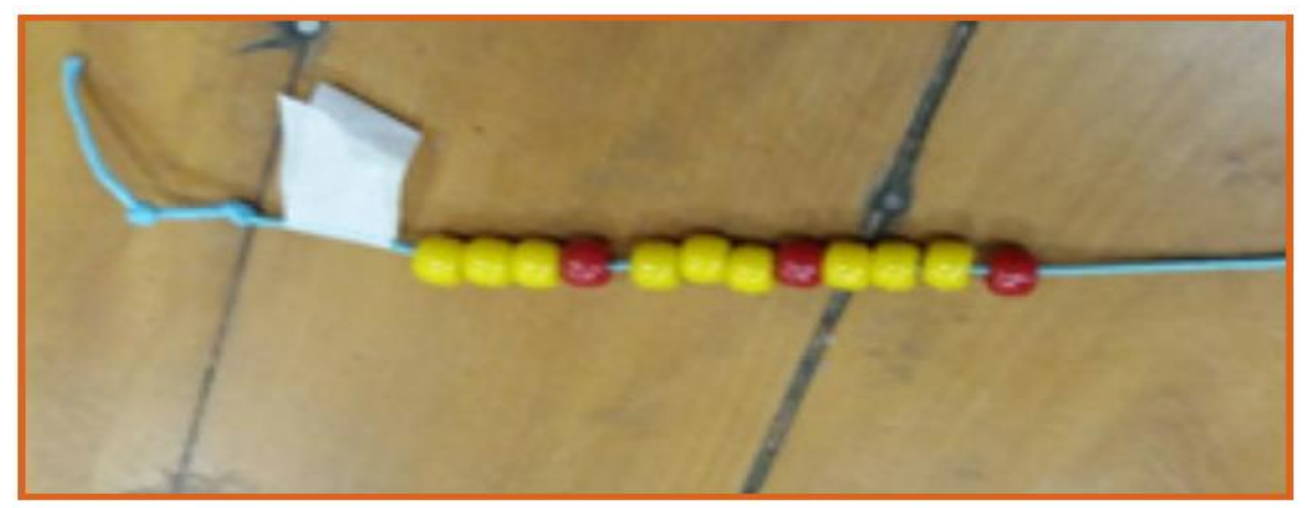

Fonte: Camargo, Bagne, Bologani e Coletti (2018, p. 68)

A orientação para o desenvolvimento de uma tarefa dessa natureza implica algumas etapas, a saber:

- Etapa 1: Distribuir a sala em grupos menores, entregar miçangas ou contas e barbantes para que fabriquem os fios de conta;

- Etapa 2: A professora poderá mostrar as crianças uma sequência pronta, inicialmente com duas cores (azul e vermelha, por exemplo). Trabalhar a sequência umas três vezes e começar a quarta repetição de modo mais autônomo por parte dos grupos;

- Etapa 3: As sequências serão compostas pelos grupos (de modo individual e/ou coletivo). Após serem organizadas em duplas e com o material em mãos, poderão criar suas sequências para que outra dupla descubra o motivo. Poderão usar duas 
ou três cores diferentes, tudo depende do contexto e da intencionalidade pedagógica.

As duas tarefas propõem a reflexão em relação aos aspectos do pensamento algébrico, destacamos aqui o reconhecimento de padrões nas sequências, como também a regularidade com que as cores se repetem, levando a turma à construir percepções dos elementos que estão ausentes nas sucessões dadas. Ponte, Branco e Matos (2009) ressaltam que a partir do momento que os alunos conseguem identificar a lei de formação de uma sequência, agregam conhecimentos necessários para a construção do sentido de número em uma determinada situação e passam a constituir fundamentos para a desenvolvimento da habilidade em identificar uma generalização.

A tarefa 2, destinada ao $2^{\circ}$ ano do Ensino Fundamental, também envolvendo sequência, desta vez inclui números, além das cores.

Figura 3 - Tira de números coloridos

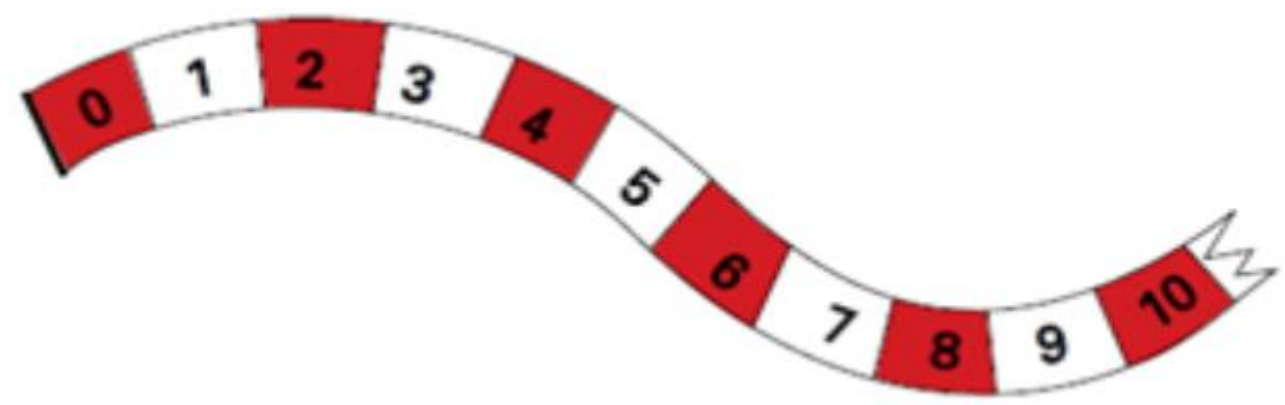

Fonte: Santos, Luvison e Moreira (2018, p. 119).

Santos, Luvison e Moreira (2018) propõem a observação da tira de papel e a alternância dos números entre as cores vermelha e branca. A princípio o professor pode desafiar os alunos a se atentarem para as cores, questionando-os sobre o que consideram existir nos espaços com cores repetidas, isso no sentido de perceber se reconhecem a alternância entre números pares e ímpares. As autoras descrevem que, ao final da tarefa, as crianças poderão estarem aptas a estabelecer relação entre as cores e a posição que os números ocupam e o reconhecimento de números pares e ímpares, sendo capazes de estabelecer uma generalização a partir dos mesmos. Em defesa de uma proposta nestes moldes em sala de aula, ainda destacam sobre a compreensão necessária das crianças em 
relação à ordem que os números ocupam na fita, a regularidade que os números são organizados, a diferença e semelhanças existentes entre a sequenciação destes elementos (SANTOS; LUVISON; MOREIRA, 2018).

Tarefas desta natureza, de acordo com os autores Ponte, Branco e Matos (2009), são relevantes para que os alunos sejam organizados em grupos pequenos e possam levantar hipóteses, raciocinar matematicamente e validá-las. Os autores, em sentido semelhante ao presente na figura 5, problematizam padrões geométricos a partir de cores e repetição figuras com indicação para exploração com crianças a partir do $2^{\circ}$ ano.

As tarefas relacionadas são importantes no sentido de contribuir para aquisição conceitual dos alunos em relação a organização de sequências, as propriedades fundamentais das figuras geométricas e a função das cores no processo de regularidade. Dessa forma, o aluno estará construindo conceitos da Álgebra no âmbito de estabelecimento de regularidades, padrões de sequências por meio de figuras, números ou símbolos, bem como compreensão de repetições, uma vez que esse processo o levará a perceber qual o elemento ausente na sequência proposta, o qual poderá inferir mentalmente a partir da abstração reflexiva.

Para o $3^{\circ}$ ano, localizamos, também no campo da sequência numérica, a tarefa 3 proposta por Ponte, Branco e Matos (2009). Neste nível de conhecimento, parte-se do pressuposto de que as crianças, em tese, conseguem estabelecer relações entre os elementos repetidos, explorando no caso as operações numéricas. A expectativa é que consigam articular os padrões de repetição por meio do conhecimento quantitativo.

Com isso, ao considerar a sequência numérica cujos dois primeiros termos são: $\mathbf{1}, \mathbf{3}, \ldots$ a professora pode perguntar quais seriam os próximos termos subsequentes e aproveitar para apresentar outras sequências crescentes onde os dois primeiros termos poderiam ser 1 e 3, exemplo:

- $\quad 1,3,5,7,9,11, \ldots$ (sequência composta por números impares, sendo que os dois termos consecutivos sempre será acrescido com dois);

- $1,3,6,10,15,21, \ldots$ (sequência baseada nos números triangulares, onde a diferença entre dois termos subsequentes possui sempre uma unidade a mais em relação a diferença dos dois algarismos anteriores);

- $1,3,7,13,21,31, \ldots$ (sequência composta pela diferença entre termos consecutivos resultando numa sequência de números pares) 
Ainda explorando aspectos da sequência numérica, podemos recorrer a algum material de fácil acesso para que as crianças consigam articular as operações com as regularidades propostas na progressão.

Em uma dinâmica semelhante a anterior (sequência numérica), agora com segmentos de retas, os alunos poderão ser organizados em duplas ou trios para que sejam distribuídos 15 palitos com uma cópia (folha A4 impressa) contendo instruções da tarefa. Em seguida, será solicitado para que organizem os palitos de acordo a sequência a seguir.

Figura 4 - Sequência de palitos (representação de segmento de reta)
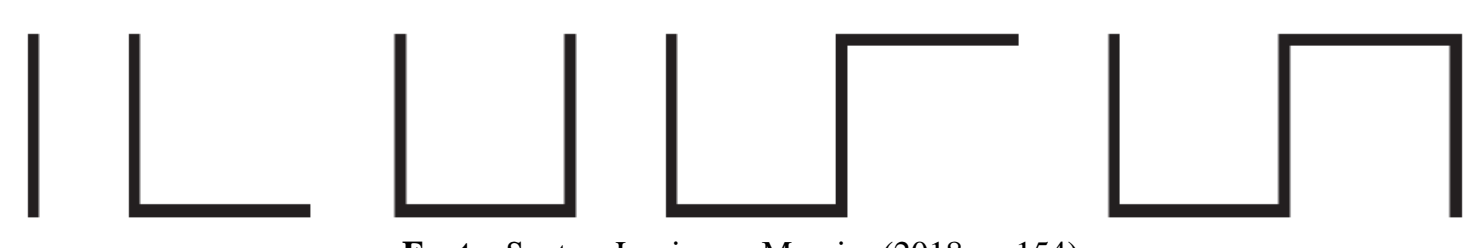

Fonte: Santos, Luvison e Moreira (2018, p. 154)

Feito isso, a professora poderá solicitar que compartilhem se perceberam algum padrão na sequência. Com a interação posta em apreciação, a imagem da folha e ainda a representação dos palitos no campo da visualização, prática da tarefa via materialização no contexto real de manipulação dos objetos, outras indagações poderão surgir como dispositivo de inferência sobre o que não se vê, ou seja, figuras que seguem o padrão dos termos. Assim, poderemos perguntar como seria a $12^{\mathrm{a}}$ figura ou de repente a $31^{\mathrm{a}}$, por exemplo, e ainda como chegaram a tal conclusão.

Para estas tarefas, cumpre salientar que no $3^{\circ}$ ano do Ensino Fundamental, estimase que as crianças conseguem identificar regularidades em sequências que exploram os números naturais, a utilização de continuidades que abordem as operações de adição e subtração. Outra tarefa, também para este mesmo nível de ensino e com os mesmos recursos pedagógicos, é perceptível que exigirá níveis de aprofundamento de percepções matemáticas além das operações. Descreve por meio de símbolos ou figuras o conceito de igualdade na perspectiva sequencial, onde o padrão de regularidade se dá na soma ou diferença de cada palito manuseado.

Seguindo esse raciocínio, Santos, Luvison e Moreira (2018) visam ampliar a tarefa com a inserção de possibilidades de experimentação, com o objetivo de construir aprendizados em relação a equivalência e compensação entre duas grandezas, como ainda 
os valores à elas correspondidos (tarefa 4). Neste caso, poderá ser desenvolvida dentro ou fora da sala de aula, momento em que as crianças (sentadas) terão uma visão de forma que enxerguem a balança. Feito isso, a professora proporá hipóteses diversas que envolvam situações de equilíbrio na balança e escolherá peças sugeridas pela turma que mantenham o mesmo peso de ambos os lados, deixando que validem suas proposições mediante a manipulação das peças e/ou objetos.

Segundo as autoras, em uma proposta exploratória de vivência prática com a Matemática, a presente tarefa pode ser desenvolvida mediante a adaptação de uma balança de dois pratos, sendo construída utilizando um cabide e dois pratinhos com correntes, utilizados para pendurar plantas, conforme figura 7 (SANTOS; LUVISON; MOREIRA, 2018).

Figura 5 - Balança

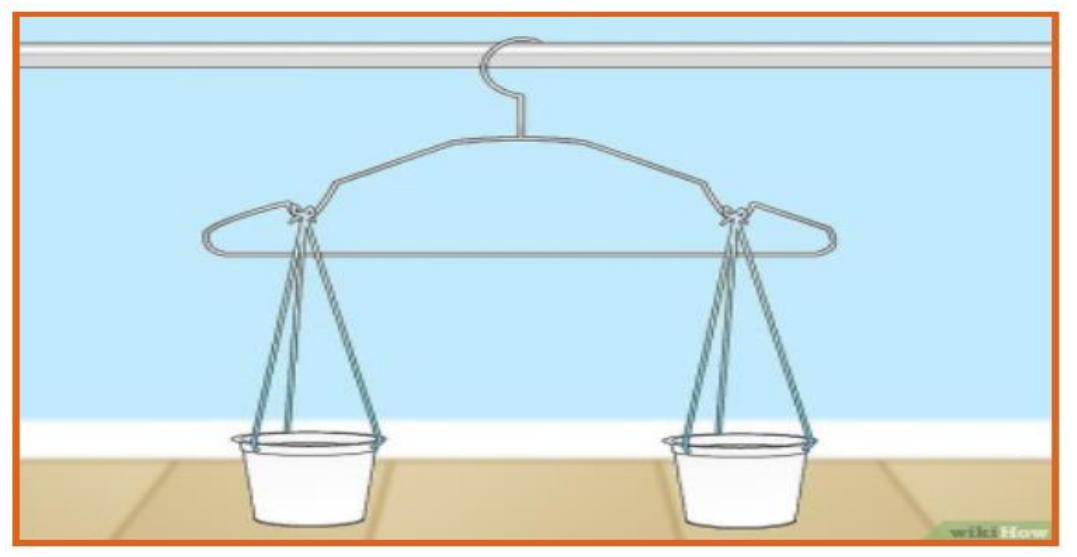

Fonte: Santos, Luvison e Moreira (2018, p. 189)

Como sugestão, poderemos dividir a sala em pequenos grupos e disponibilizar uma balança com as barras e o papel quadriculado. A atividade das crianças será encontrar as possibilidades de equilíbrio e efetuar o registro no papel quadriculado.

Para finalizar, é indicado que seja promovida a socialização onde cada aluno terá a oportunidade de explicitar sua descoberta e interagir com as situações apresentadas pelos demais colegas.

A expectativa com a tarefa das balanças é que os alunos compreendam, por meio das estratégias desenvolvidas, as relações de equivalência. Outro conhecimento do raciocínio algébrico implícito aqui é a compreensão da ideia de igualdade, onde a 
equiparação dos elementos descritos na balança indicaria às crianças o entendimento de correspondência nos resultados, estes explorados mediante as operações aritméticas.

\section{Conclusão}

Ao longo do presente artigo propusemo-nos dialogar com o campo teórico da necessidade de inserção do pensamento algébrico nos anos iniciais do Ensino Fundamental. Buscamos na literatura nacional e internacional contributos para sua definição, emergência e possibilidades. Como forma de contribuir para os estudos da área, frente a propositura do trabalho de mestrado em desenvolvimento por nós, descrevemos e analisamos algumas tarefas que envolvem ideias algébricas para turmas de $1^{\circ}, 2^{\circ}$ e $3^{\circ}$ ano, contexto basilar para a formação do pensamento matemático das crianças.

A experiência de contato direto com os encartes tanto do e-book brasileiro (NACARATO; CUSTÓDIO, 2018) quanto do material de Portugal (PONTE; BRANCO; MATOS, 2009) possibilitou clarificar do que estamos a falar, de modo prático, com exemplos de tarefas que exprimem caminhos para o fazer pedagógico do professor que ensina Matemática nos anos iniciais. Destacamos que existem muitas outras habilidades de desenvolvimento do pensamento algébrico com as crianças, as quais indicam necessidade de uma abordagem de ensino exploratória, contextualizada e situada, que incentivem a autonomia e protagonismo infantil. Para nós, a partir da apreciação objeto de diálogo com o leitor neste texto, uma abordagem de ensino que vá ao encontro das tendências em Educação Matemática pode ser um itinerário pedagógico rico e promissor a ser explorado.

\section{Referências}

BLANTON, Maria L.; KAPUT, James J. Characterizing a classroom practice that promotes algebraic reasoning. Journal for Research in Mathematics Education, Reston, v. 5, n. 36, p. 412-446, 2005.

BOGDAN, Roberto C.; BIKLEN, Knopp Sari. Investigação qualitativa em educação: uma introdução à teoria e aos métodos. Portugal: Porto Editora, 1994.

BRASIL. Ministério da Educação. Base Nacional Comum Curricular. Brasília: MEC/SEB, 2018. Disponível em: 〈http://basenacionalcomum.mec.gov.br>. Acesso em: 06, abr. 2020. 
CAMARGO, Giancarla Giovanelli de; BAGNE, Juliana; BOLOGNANI, Marjorie Samira Ferreira; COLETTI, Selene. Desenvolvimento do pensamento algébrico com crianças?... possibilidades de práticas na educação infantil. In: NACARATO, Adair Mendes; CUSTÓDIO, Íris A. (Orgs.), O desenvolvimento do pensamento algébrico na Educação Básica: compartilhando propostas de sala de aula com o professor que ensina (ensinará) Matemática. Brasília: Sociedade Brasileira de Educação Matemática, 2018, p. 13-23. Disponível em 〈http://www.sbembrasil.org.br/files/ebook_desenv.pdf>. Acesso em: 15 nov. 2020.

CANAVARRO, Ana Paula. O pensamento algébrico na aprendizagem da Matemática nos primeiros anos. Quadrante. Vol. 16, n. 2, 2007. Disponível em: <https://dspace.uevora.pt/rdpc/bitstream/10174/4301/1/_Quadrante_vol_XVI_2-2007pp000_pdf081-118.pdf>. Acesso em: 06, abr. 2020.

CASTRO, Mônica Rabello. Educação algébrica e Resolução de problemas. Boletim Salto para o Futuro - TV Escola. Maio 2003. Disponível em:

$<$ https://cdnbi.tvescola.org.br/contents/document/publicationsSeries/110456EducacaoAl gebricaResolucaoProblemas.pdf>. Acesso em: 07, abr. 2020.

KAPUT, James J.; BLANTON, Maria L.; MORENO, Luis. Algebra from a symbolization point of view. In: KAPUT, James J; CARRAHER, David; BLANTON, Maria L. (Eds.). Algebra in the Early Grades New York: Lawrence Erlbaum Associates, 2008. p.133-160.

MEIRA, Luciano. Significados e modelagem na atividade algébrica. Boletim Salto para o Futuro - TV Escola. Maio 2003. Disponível em:

<https://cdnbi.tvescola.org.br/contents/document/publicationsSeries/110456EducacaoAl gebricaResolucaoProblemas.pdf>. Acesso em: 07, abr. 2020.

NACARATO, Adair Mendes; CUSTÓDIO, Iris Aparecida. O desenvolvimento do pensamento algébrico: algumas reflexões iniciais. In: NACARATO, A. M.;

CUSTÓDIO, I. A. (Orgs.). O desenvolvimento do pensamento algébrico na

Educação Básica: compartilhando propostas de sala de aula com o professor que ensina (ensinará) Matemática. Brasília: Sociedade Brasileira de Educação Matemática, 2018, p. 13-23. Disponível em 〈http://www.sbembrasil.org.br/files/ebook_desenv.pdf $>$. Acesso em: 15, nov. 2020.

PONTE, João Pedro da; BRANCO, Neusa; MATOS, Ana. Álgebra no Ensino Básico. Portugal: Ministério da Educação e Direção Geral de Inspeção e Desenvolvimento Curricular (DGIDC), 2009. Disponível em: <https://repositorio.ul.pt/bitstream/10451/7105/1/Ponte-BrancoMatos\%20\%28Brochura_Algebra\%29\%20Set\%202009.pdf>. Acesso em: 15, jan. 2021.

PONTE, João Pedro da; BRANCO, Neusa. Pensamento algébrico na formação inicial de professores. Educar em Revista, Curitiba, Brasil, n. 50, p. 135-155, out./dez. 2013. Disponível em: 〈https://www.scielo.br/pdf/er/n50/n50a10.pdf> . Acesso em: 06, abr. 2020. 
SANTOS, Carla Cristiane Silva; LUVISON, Cidinéia da Costa; MOREIRA, Kátia Gabriela. A construção do pensamento algébrico no Ensino Fundamental I: possíveis trabalhos para a percepção de regularidades e de generalizações. In: NACARATO, Adair Mendes; CUSTÓDIO, Íris. (Orgs.). O desenvolvimento do pensamento algébrico na Educação Básica: compartilhando propostas de sala de aula com o professor que ensina (ensinará) Matemática. Brasília: Sociedade Brasileira de Educação Matemática, 2018, p. 13-23. Disponível em:

<http://www.sbembrasil.org.br/files/ebook_desenv.pdf >. Acesso em: 15, nov. 2020.

Recebido em: 28 / 02 / 2021

Aprovado em: 20 / 04 / 2021 